\title{
Anaesthetic management of a super morbidly obese patient for total abdominal hysterectomy: a few more lessons to learn
}

\author{
*Fyneface-Ogan $\mathrm{S}^{1}$, Abam $\mathrm{DS}^{2}$, Numbere $\mathrm{C}^{1}$ \\ 1. Department of Anaesthesiology, Faculty of Clinical Sciences, College of Health Sciences, University of Port Harcourt, \\ Port Harcourt, Nigeria \\ 2. Nimley Hospital for Women, 17 Churchill Road, Port Harcourt, Nigeria
}

\begin{abstract}
Background: The prevalence of obesity is on the upward trend world-wide. This epidemic has challenging implications for anaesthetists, following the anthropometric changes associated with the disease.

Objective: To highlight some of the challenges, the management and the lessons learnt during the management of this patient.

Methods: This is a case report of a 52-year old super morbidly obese, diabetic, and hypertensive patient that presented for total abdominal hysterectomy. Surgery was carried out under a single-shot spinal anaesthesia with bupivacaine/fentanyl.

Results: Under bupivacaine/fentanyl anaesthesia, she became very drowsy and had moderate to severe respiratory depression. She was arousable but had an obstructive sleep apnoea. Surgery was carried out successfully

Conclusion: A better understanding of the pathophysiology and complications that accompany obesity is needed to manage an obese patient under anaesthesia.

African Health Sciences 2012; 12(2): 181 - 185 http://dx.doi.org/10.4314/ahs.v12i2.16
\end{abstract}

\section{Introduction}

The prevalence of obesity is on the upward trend world-wide ${ }^{1,2}$. In the United States of America, the incidence of obesity has doubled over the past 20 years ${ }^{1}$. The extent of obesity is usually quantified through the body mass index (BMI), which is defined as the relationship between height and weight (weight $[\mathrm{kg}] /$ height $\left.^{2}\left[\mathrm{~m}^{2}\right]\right)$. The BMI is divided into five categories: $<25 \mathrm{~kg} / \mathrm{m}^{2}=$ normal, $25-30 \mathrm{~kg} / \mathrm{m}^{2}=$ overweight, $>30 \mathrm{~kg} / \mathrm{m}^{2}=$ obesity, $>35 \mathrm{~kg} / \mathrm{m}^{2}=$ morbid obesity, $>55 \mathrm{~kg} / \mathrm{m}^{2}=$ super morbid obesity 3.

Obesity is frequently associated with challenges during anaesthesia. Following this, the use of regional anaesthetic techniques for obese patients is increasing in popularity as this offers distinct advantages over general anaesthesia for these patients. Regional anaesthesia (RA) offers several advantages when treating obese patients, including minimal airway intervention, less cardiopulmonary depression,

\begin{tabular}{|l|}
\hline *Correspondence author: \\
Dr S. Fyneface-Ogan \\
Department of Anaesthesiology \\
Faculty of Clinical Sciences \\
College of Health Sciences \\
University of Port Harcourt \\
Port Harcourt, Nigeria \\
Phone: +234-8033-426-236 \\
Email: soglonye@yahoo.com
\end{tabular}

African Health Sciences Vol 12 No 2 June 2012 improved postoperative analgesia ${ }^{4,5}$, decreased opioid consumption, decreased postoperative nausea and vomiting (PONV) ${ }^{5,6}$, and therefore reduced post-anaesthesia care unit $(\mathrm{PACU})^{7}$ and hospital length of stay ${ }^{5}$. Moreover, RA has been associated with improved postoperative analgesia ${ }^{5}$, particularly when long-acting local anaesthetics ${ }^{8}$, or continuous peripheral nerve blocks ${ }^{9}$, are used. Despite these advantages, RA can be technically challenging in the obese. These challenges are related to difficulties in patient positioning, identifying the usual bony and muscular landmarks, and the depth of needle penetration ${ }^{2}$. However, the limitations of regional anaesthesia and the technical difficulties encountered with its use in obese patients must be carefully considered.

We report a super-morbidly obese woman that presented for a total abdominal hysterectomy. The anaesthetic management is discussed and the learning points highlighted.

\section{Case report}

A 53 year old super morbidly obese female, total body weight $165 \mathrm{~kg}$, with a height of $168 \mathrm{~cm}$ (BMI=58.5), presented with a history of bleeding per vaginam and abdominal mass of 3 years duration. She had both severe hypertension and moderately controlled type 2 diabetes mellitus for which she had been on treatment for more than 10 years with 
amlodipine $10 \mathrm{mg}$, glibenclamide $5 \mathrm{mg}$ twice daily, metformin $1000 \mathrm{mg}$ thrice daily, atorvastatin $10 \mathrm{mg}$ daily and low dose aspirin $75 \mathrm{mg}$ daily.

She had two previous caesarean sections and an appendectomy. Further history revealed over five years of witnessed snoring, relative difficulty staying awake during the day, choking and coughing bouts at night, awakening from sleep multiple times during the night, and morning fatigue suggestive of obstructive sleep apnoea. Sleep study could not be performed in our centre to confirm the degree of sleep efficiency and apnoea/hypopnoea index.

\section{Figure: Showing the posterior view of the patient}

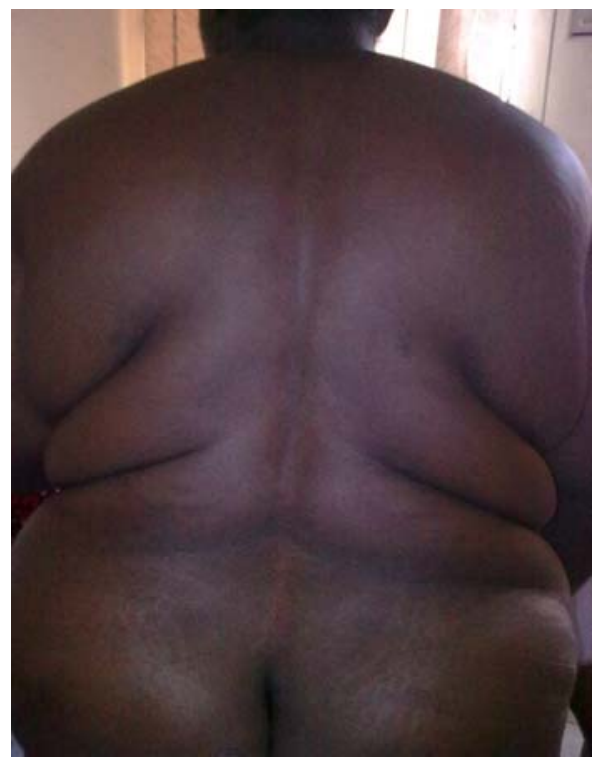

Examination of the lower back could not reliably show a normal vertebral column and bony landmarks as a result of massive fatty tissues. Airway examination revealed an apparently normal dentition and Mallampati classification III. Following inadequate thyro-mental and sterno-mental distances and, an excessive breast mass difficulty in laryngoscopy and tracheal intubation were anticipated. The patient was classified as American Society of Anaesthesiologists physical status Class IV.

The electrocardiographic findings were a tall $R$ wave (greater than $25 \mathrm{~mm}$ in V6), a deep $S$ waves in V1, inverted T waves in V5 and ST depression; the QRS was slightly prolonged in keeping with left ventricular hypertrophy and left axis deviation. Fasting blood glucose on the morning of surgery was $7.5 \mathrm{mmol} / \mathrm{L}$ (normal $5.2-7.0 \mathrm{mmol} / \mathrm{L}$;
ONETOUCH Ultra2, Lifescan, Inc, Milpitas, USA). All other biochemical parameters were normal.

On the day of surgery, she had her routine amlodipine and atorvastatin tablets only. Two extralong laryngoscope blades with short barrel handles, a cricothyrotomy set, and laryngeal mask airway were made ready for anticipated difficult airway instrumentation and access. Following the expected airway difficulties, regional anaesthesia was planned although we were fully prepared for tracheal intubation and full ventilatory support should she develop any respiratory problems. Details of the techniques chosen were discussed with her. After securing $18 \mathrm{G}$ intravenous line on the dorsum of the left hand, we attched monitors such as pulse oximeter, precordial stethoscope and non-invasive blood pressure monitor. She was also tested and confirmed for adequacy of mask ventilation.

Pre-induction of anaesthesia baseline variables showed that the blood pressure was 160/ $105 \mathrm{mmHg}$, pulse- $102 / \mathrm{min}$, and $\mathrm{SPO}_{2}$ was $94-95 \%$ on room air. The "no insulin, no glucose" technique was decided to be used within the intraoperative period. Half a litre of normal saline was commenced as preload. For the induction of spinal anaesthesia, she was positioned sitting with the feet resting on a stool. While observing asepsis, and using the L3/4 intervertebral space, the subarachnoid space was located after three attempts with an extra-long (115 mm long) 25-gauge pencil-point spinal needle passed through a size $20 \mathrm{G}$ Tuohy needle as a guide. Spinal anaesthesia was carried out using bupivacaine heavy $10 \mathrm{mg} /$ fentanyl 25 micrograms. After a light dressing was placed at the puncture site, she was returned supine with $20^{\circ}$ head up and $15^{\circ}$ left lateral tilt. Diclofenac suppository $200 \mathrm{mg}$ was inserted for pre-emptive analgesia before she was cleaned and draped and, skin incision made. A maximum T5/ T6 sensory level was achieved after 5 minutes. Oxygen (3-4 L/min) was administered to her via a face mask.

Intraoperatively, she was found to be very drowsy, and was assessed to be on the RAMSAY Sedation Score (RSS) 5 (Sluggish response to stimulus). She however, had fairly stable cardiovascular parameters. The mean arterial blood pressure was between 85 and $110 \mathrm{mmHg}$ with normal heart rates. An intermittent brief period of rise in systolic blood pressure was observed. This corresponded to the periods of obstructive apnoea. An oropharyngeal airway size 5 was eventually passed while oxygen by face mask was maintained. During 
the periods of verbal contacts, she confirmed having adequate intraoperative analgesia but complained of severe drowsiness. The surgery lasted for 168 mins. She was transferred with the aid of 8 hospital staff to the theatre trolley and then to the ward. Oxygen by face mask continued until the drowsiness subsided. Opioid analgesia was avoided throughout the postoperative period. She was managed with diclofenac $200 \mathrm{mg}$ suppository 12 hourly and intravenous paracetamol $400 \mathrm{mg} \quad 6$ hourly for 48 hours. She also received enoxaparin $40 \mathrm{mg} 12$ hourly for 48 hours and encouraged for early mobilisation. She was however discharged from the hospital on the $9^{\text {th }}$ day postoperative.

\section{Discussion}

Obese surgical patients pose multiple challenges to the anaesthetist. One of the challenges is as a result of the anthropometric changes associated with the disease. Obesity is also associated with an increased incidence of medical co-morbidities; including noninsulin dependent diabetes, hypertension, and decrease in sleep efficiency associated with sleep apnoea, cardiopulmonary disease, venous thromboembolism, and psychosocial disease. Our patient had a BMI of 58.5 and had been on treatment for diabetes and severe hypertension.

One of the frequent complications associated with this degree of obesity is obstructive sleep apnoea (OSA). The diagnosis of OSA could not be made as our centre is not equipped to carry out sleep study to ascertain the degree of sleep efficiency and apnoea/hypopnoea index. A high index of suspicion of OSA was based on five years of witnessed snoring, relative difficulty staying awake during the day, choking and coughing bouts at night, awakening from sleep multiple times during the night, and morning fatigue. However this disease entity may be replicated following a high spinal anaesthesia as the de-afferentation of peripheral stimuli results in an altered level of arousal. This is an important consideration in our patient as the disease could have manifested itself for the first time during the course of anaesthesia.

The option of regional anaesthesia was chosen following an anticipation of a difficult airway management, although we were fully prepared for tracheal intubation and full ventilatory support should she develop any respiratory compromise. Regional anaesthesia offers several advantages when treating obese patients, including minimal airway intervention, less cardiopulmonary depression, improved postoperative analgesia ${ }^{4}, 5$, decreased opioid consumption, decreased postoperative nausea and vomiting (PONV) ${ }^{5,6}$, and therefore reduced postanaesthesia care unit $(\mathrm{PACU})^{7}$ and hospital length of stay $^{5}$. Despite these advantages, RA can be technically challenging in the obese. These challenges are related to difficulties in patient positioning, identifying the usual bony and muscular landmarks, and the depth of needle penetration ${ }^{2}$. In our patient, the challenge of the depth of needle penetration was overcome with the use of a size $20 \mathrm{G}$ Tuohy needle as a guide to pass the $115 \mathrm{~mm}$ long pencil point spinal needle.

Another challenge encountered during the intraoperative anaesthetic management of this patient was the maintenance of adequate peripheral tissue oxygenation. The peripheral oxygen saturation was very low inspite of oxygen by mask. This could be due to respiratory depression following the administration of the intrathecal bupivacaine/fentanyl mixture. It has been demonstrated that opioid and sedative drugs cause respiratory depression in the morbidly obese $\mathrm{e}^{10}$ and are probably best avoided, although one study failed to demonstrate an increased risk of oxyhaemoglobin desaturation with benzodiazepines ${ }^{11}$. The intramuscular and subcutaneous routes, however, should be avoided, since absorption is very unreliable ${ }^{10,12}$. The aim of introducing the intrathecal opioid was to produce a synergistic and more prolonged effect from the local anaesthetic agent. Although it prolonged the duration of analgesia in our patient, the opioid produced an additional challenge to us. One important lesson to learn from the management of this patient is the ability to prevent, recognize early, and treat respiratory depression following the use of this combination of agents. Treatment protocols and mechanisms to ensure a rapid response to respiratory events should also be in place.

Our experience also leads us to suggest that all patients who have received neuraxial anaesthesia along with opioid, should also be monitored with capnometer, regardless of their past medical history. This is also true if an intravenous sedation will be required, as it has been shown that patients with spinal anaesthetics exhibit increased sensitivity to sedating agents $^{13}$.

Non-obstetric studies report an incidence of respiratory depression after neuraxial opioids of $0.01 \%-7 \% .^{14,15}$ Retrospective, observational studies may under-estimate the true incidence. Also, the fact that there is no standard definition of respiratory depression ${ }^{16}$ may contribute to under-/over- 
estimating the incidence. Respiratory rate, hypercarbia, low $\mathrm{SpO}_{2}$, sedation, depressed ventilatory response to hypoxia or hypercarbia, and naloxone treatment have all been used as indicators of respiratory depression ${ }^{16}$. Our patient was very drowsy and had moderate respiratory depression. The introduction of an oropharyngeal airway relieved the obstruction that accompanied the respiratory depression.

Our patient displayed an altered level of consciousness, bradypnoea, and hypoxemia that required both treatment and more intensive monitoring until the symptoms resolved. Although supplemental oxygen was available and administered, its routine use is not recommended, because it may increase the duration of apnoea and reduce the sensitivity of pulse oximetry for detecting hypoventilation ${ }^{17}$. Naloxone was indicated in this patient but was not used. Its use would have reversed the effect of the intrathecal opioid on the duration of intraoperative analgesia, hence the use of prompt mask ventilation with oxygen source and the readiness for tracheal intubation. It is also worthy to note that the routine administration of prophylactic naloxone is not recommended ${ }^{18}$.

The use of opioid analgesics may be hazardous in the obese patient. Acute opioid use reduces vital ventilatory chemoreflexes as well as upper airway patency; therefore Obstructive Sleep Apnoea (OSA) is a major risk factor for postoperative morbidity and mortality. However, there is a large inter-individual variability among OSA patients and normal individuals in response to opioids. It is important to develop a clinically useful approach to identify those individuals most vulnerable to opioid-induced respiratory depression. The intramuscular route for opioid administration is not recommended as it is unpredictable and has been shown to provide poorer analgesia than other routes ${ }^{19}$, ${ }^{20}$. Our patient received diclofenac suppository alternating with intravenous paracetamol for postoperative pain relief. This was as a result of the observed intraoperative event of respiratory depression and hypoxaemia. However, if the intravenous route is to be used, then a PatientControlled Analgesia System (PCAS) is probably the best option ${ }^{21}$. This analgesic delivery device was not available in our setting. The PCAS has been shown to provide effective analgesia in the obese, although respiratory depression has also been reported ${ }^{22}$. Doses should be based on ideal body weight of the patient $^{23}$. Supplemental oxygen and close observation, including pulse oximetry monitoring, are recommended.

Another major challenge in the course of the anaesthetic management of our patient was her transfer to and from the operating room. The safest transfer of an obese patient is probably one where the un-premedicated patient climbs off their hospital bed and positions themselves on the Operating Table (OT). The patient is then anaesthetised on the OT table (versus in induction room). Our patient was encouraged to walk into the operation room and she eventually climbed the OT with minimal support. The ability to do this minimizes injury to both the patient and staff involved. Once on the OT, all pressure points were carefully padded to avoid pressure sores and neurological injury. It is known that morbidly obese patients are at an increased risk for compression and neurological injuries ${ }^{24}$. She was adequately padded at the pressure points and areas prone to injury.

In the supine position, the Functional Residual Capacity (FRC) is markedly decreased, and this together with an already reduced FRC, expiratory reserve volume, and total lung capacity, results in a ventilation perfusion mismatch and significant increases in oxygen consumption, cardiac output, and pulmonary artery pressures. The reverse trendelenberg position (20 degrees) was best tolerated in our patient. This position results in unloading of the diaphragm, having the same effect as positive end expiratory pressure ${ }^{25}$. The left lateral tilt displaced the huge uterine mass to avoid inferior vena caval compression.

\section{Conclusion}

Obesity is no longer an epidemic in the western world, but rather a worldwide pandemic. Clearly the conduct of anaesthesia in a morbidly obese patient can pose a formidable challenge to the anaesthetist and intensive care staff. A better understanding of the pathophysiology and complications that accompany obesity may improve their care and outcome.

\section{Acknowledgement}

We wish to thank our patient for allowing us to publish her photograph in this case report.

\section{References}

1. Flegal KM, Carroll MD, Ogden CL, Johnson CL. Prevalence and trends in obesity among US adults, 1999-2000. JAMA 2002; 288: 1723 1727.

African Health Sciences Vol 12 No 2 June 2012 
2. Adams JP, Murphy PG. Obesity in anaesthesia and intensive care. Br J Anaesth 2000; 85: 91108.

3. Bray GA. Pathophysiology of obesity. Am J Clin Nutr 1992; 55: 488 S-94.

4. Pusch F, Freitag H, Weinstabl C, Obwegeser R, Huber E, Wildling E. Single-injection paravertebral block compared to general anaesthesia in breast surgery. Acta Anaesthesiol Scand 1999; 43: 770-774.

5. Coveney E, Weltz CR, Greengrass R, Iglehart JD, Leight GS, Steele SM, Lyerly HK. Use of paravertebral block anaesthesia in the surgical management of breast cancer: experience in 156 cases. Ann Surg 1998; 227: 496-501.

6. Lynch EP, Welch KJ, Carabuena JM, Eberlein TJ. Thoracic epidural anaesthesia improves outcome after breast surgery. Ann Surg 1995; 222: 663-669.

7. D'Alessio JG, Rosenblum M, Shea KP, Freitas DG. A retrospective comparison of interscalene block and general anaesthesia for ambulatory surgery shoulder arthroscopy. Reg Anesth 1995; 20: 62-68.

8. Klein SM, Nielsen KC, Greengrass RA, Warner DS, Martin A, Steele SM. Ambulatory discharge after long-acting peripheral nerve blockade: 2382 blocks with ropivacaine. Anesth Analg 2002; 94: 65-70.

9. Grant SA, Nielsen KC, Greengrass RA, Steele SM, Klein SM: Continuous peripheral nerve block for ambulatory surgery. Reg Anesth Pain Med 2001; 26: 209-214.

10. Vaughan RW. Anaesthetic management of the morbidly obese patient. In: Brown BR, Blitt CD, Giesecke AH, Vaughan RW, eds. Anesthesia and the Obese Patient. New York: Davis, 1982; 7194

11. Bilotta JJ, Floyd JL, Waye JD. Arterial oxygen desaturation during ambulatory colonoscopy: predictability, incidence and clinical insignificance. Gastrointest Endosc 1990; 36: S5-8.

12. Cooper JR, Brodsky JB. Anaesthetic management of the morbidly obese patient. Semin Anesth 1987; 6: 260-270.

13. Gentili M, Chau Huu P, Enel D, Hollande J, Bonnet F. Sedation depends on the level of sensory block induced by spinal anaesthesia. $\mathrm{Br}$ J Anaesth 1998; 81: 970-971.

14. Horlocker TS. Practice guidelines for the prevention, detection and management of respiratory depression associated with neuraxial opioid administration: Preliminary Report by ASA Task Force on neuraxial anaesthesia. ASA Newsletter 2007; 71: 24-26.

15. Shapiro A, Zohar E, Zaslansky R, Hoppenstein D, Shabat S, Fredman B. The frequency and timing of respiratory depression in 1524 postoperative patients treated with systemic or neuraxial morphine. J Clin Anesth 2005; 17: 537542.

16. Ko S, Goldstein DH, VanDenKerkhof EG. Definitions of "respiratory depression" with intrathecal morphine postoperative analgesia: a review of the literature. Can J Anaesth 2003; 50: 679-688.

17. Weinger M. Dangers of postoperative opioids. APSF Newsletter 2007; 21: 61-68.

18. Ready LB, Loper KA, Nessly M, Wild L. Postoperative epidural morphine is safe on surgical wards. Anesthesiology 1991; 75: 452-456.

19. Brodsky JB, Merrel RC. Epidural administration of morphine postoperatively for morbid obese patients. W J Med 1984; 140: 750-753.

20. Rawal N, Sjöstrand U, Christofferson E, Dahlström B, Arvill A, Rydman H. Comparison of intramuscular and epidural morphine for postoperative analgesia in the grossly obese. Influence on postoperative ambulation and pulmonary function. Anesth Analg 1984; 63: 583592.

21. Bennett R, Batenhorst R, Graves DA, Foster TS, Griffen WO, Wright BD. Variation in postoperative analgesic requirements in the morbidly obese following gastric bypass surgery. Pharmacotherapy 1982; 2: 50-53

22. VanDercar DH, Martinez AP, De Lisser EA. Sleep apnoea syndromes: a potential contraindication for patient-controlled analgesia. Anesthesiology 1991; 74: 623-624.

23. Shenkman Z, Shir Y, Brodsky JB. Perioperative management of the obese patient. BrJ Anaesth 1993; 70: 349-359.

24. Schulz-Stubner S. Bilateral occipital neuropathy as a rare complication of positioning for thyroid surgery in a morbidly obese patient. Acta Anaesthesiol Scand 2004; 48: 126-127.

25. Perilli V, Sollazzi L, Modesti C, Annetta MG, Sacco T, Bocci MG, Tacchino RM, Proietti R. Comparison of positive end expiratory pressure with reverse Trendelenburg position in morbidly obese patients undergoing bariatric surgery: effects on hemodynamics and pulmonary gas exchange. Obes Surg 2003; 13: 605-609. 